\title{
CDC25A inhibition suppresses the growth and invasion of human hepatocellular carcinoma cells
}

\author{
XUNDI XU ${ }^{1,2}$, HIROFUMI YAMAMOTO ${ }^{1}$, GUOXING LIU ${ }^{2}$, YASUHIRO ITO $^{1}$, CHEW YEE NGAN $^{1}$, \\ MOTOI KONDO ${ }^{1}$, HIROAKI NAGANO $^{1}$, KEIZO DONO $^{1}$, MITSUGU SEKIMOTO ${ }^{1}$ and MORITO MONDEN ${ }^{1}$ \\ ${ }^{1}$ Department of Surgery, Gastroenterological Surgery, Graduate School of Medicine, Osaka University, \\ Osaka 565-0871, Japan; ${ }^{2}$ Department of Surgery, Xiangya Second Hospital, \\ Central South University, Changsha, Hunan province 410011, P.R. China
}

Received May 31, 2007; Accepted July 9, 2007

\begin{abstract}
CDC25A is a cell cycle-activating phosphatase that promotes transition from the G1 to $\mathrm{S}$ phase. We previously reported that overexpression of CDC25A in human hepatocellular carcinoma (HCC) tissue samples was associated with poor prognosis. In this study, we attempted suppression of CDC25A in HCC cells to elucidate the therapeutic potential of this approach. Administration of CDC25A antisense (AS) oligonucleotide resulted in $25-50 \%$ inhibition of cell growth at $48 \mathrm{~h}, \mathrm{G} 0-\mathrm{G} 1$ arrest, and significant inhibition of cancer cell invasion. To elucidate the underlying mechanism of the inhibitory effects of HCC cell invasion, we examined several invasion-associated molecules, and we found that membranetype 3 (MT3)-matrix metalloproteinase (MMP) mRNA was greatly reduced following treatment with AS oligonucleotide to CDC25A or siRNA treatment. Notably, screening of a panel of gastrointestinal cancer cells indicated that MT3-MMP was generally expressed by HCC cells, whereas other cell types did not express this type of matrix metalloproteinase so frequently. We also found that CDC25A facilitated cellular differentiation by increasing albumin expression in the PLC cell line. These results suggest that CDC25A, by inhibiting HCC growth and invasion, may be a feasible therapeutic target for human HCC.
\end{abstract}

Correspondence to: Dr Hirofumi Yamamoto, Department of Surgery, Gastroenterological Surgery, Graduate School of Medicine, Osaka University, 2-2 Yamada-oka, Suita-City, Osaka 565-0871, Japan

E-mail: kobunyam@surg2.med.osaka-u.ac.jp

Abbreviations: AS, antisense; CDK, cyclin-dependent kinase; dsRNAs, double-stranded RNAs; HCC, hepatocellular carcinoma; MMP, matrix metalloproteinase; MM, mismatch; PBGD, porphobilinogen deaminase; PCNA, proliferating cell nuclear antigen; RTPCR, reverse transcriptase-polymerase chain reaction; siRNA, short interfering RNA

Key words: CDC25A, membrane-type 3-matrix metalloproteinase, hepatocellular carcinoma, invasion, differentiation

\section{Introduction}

Primary hepatocellular carcinoma (HCC) is the third leading cause of cancer death worldwide, with an estimated 564,000 new cases in 2000 (1). Frequent postoperative recurrence of the disease, characterized by intrahepatic metastasis or multicentric carcinogenesis, is one of the major reasons for the poor prognosis of $\operatorname{HCC}(2,3)$. Insight into the molecular mechanisms involved in hepatocarcinogenesis may enable more effective treatment for HCC.

CDC25 genes are cell cycle-activating phosphatases that remove the inhibitory phosphates of threonine and tyrosine residues at the ATP-binding sites of cyclin-dependent kinase. Three CDC25 genes, CDC25A, CDC25B, and CDC25C, which share $\sim 40-50 \%$ amino acid identity, have been identified and function during different stages of the cell cycle, including G1-S and G2-M transition (4-7). It has been found that CDC25A and CDC25B, but not CDC25C, possess oncogenic potential and are able to transform primary murine fibroblasts in cooperation with either mutated Ha-ras or loss of Rb1 (8). Furthermore, concordant in vitro and in vivo findings show that $\mathrm{CDC} 25 \mathrm{~A}$ and $\mathrm{CDC} 25 \mathrm{~B}$ are overexpressed in various types of human malignancies, including HCC (9-14).

Accumulating evidence suggests that several molecules acting at the G1-S transition of the cell cycle play crucial roles in the progression of HCC. HCC tissues overexpress cyclins D1 and E $(15,16)$. In a subset of HCCs, expression of the cyclin-dependent kinase (CDK) inhibitor $\mathrm{p} 21^{\text {wafl/cip } 1}$ was reduced, the $\mathrm{p} 16^{\mathrm{INK} 4}$ gene was methylated at the promoter region, and expression of $\mathrm{p} 27^{\mathrm{Kip} 1}$ appeared to be decreased $(15,17,18)$. We previously found that CDC25A, rather than CDC25B, was overexpressed in the dedifferentiated phenotype of HCC and that its levels correlated with hypergrowth activity (14). We also found that CDC25A overexpression was associated with shorter disease-free survival of patients with HCC. Foundational research showed that ablation of CDC25A function by microinjection of a specific antibody blocks cell entry into $S$ phase (5). Conversely, inducible overexpression of CDC25A, leading to activation of cyclin E-Cdk2 and cyclin A-Cdk2, revealed that these complexes act as critical targets for CDC25A $(19,20)$. This evidence suggests the relevance of CDC25A to G1-S transition. Based 
on these findings, in the present study, we explored the therapeutic potential and biological effects of antisense (AS) oligonucleotides against CDC25A in HCC cells.

\section{Materials and methods}

AS oligonucleotides and short interfering RNA. All oligodeoxynucleotides as well as FITC-conjugated oligonucleotides were synthesized by a DNA synthesis facility (Sigma-Aldrich Co., St. Louis, MO) and contained phosphorothioate linkages at the first two and last three internucleotide bonds. The CDC25A AS oligonucleotide (5'-CCGCGGCG GTACCTTGAC-3') was designed to be complementary to the translation start site of the CDC25A gene. As a control, mismatch (MM) oligonucleotides with four (MM-1, CCG CTGCAGTGCCGTGAC) and six base mismatches (MM-2, CAGCTGCAGTGCCGTGCC) were prepared.

RNA duplexes [short interfering RNA (siRNA)] directed against the CDC25A gene were synthesized and purchased from Qiagen (Hilden, Germany). The sequences of the siRNA for CDC25A and the negative control were 5'-GGC GCUAUUUGGCGCUUCA-3' and 5'-ATCCGCGCGAT AGTACGTA-3', respectively.

Cell culture and transfection. The HCC cell lines HepG2, $\mathrm{PLC} / \mathrm{PRF} / 5$ (hereafter designated as PLC), and Huh7 were obtained from the American Type Culture Collection (Manassas, VA). The cells were grown in DMEM supplemented with $10 \%$ fetal bovine serum, 100 units $/ \mathrm{ml}$ penicillin, and $100 \mu \mathrm{g} / \mathrm{ml}$ streptomycin in $5 \% \mathrm{CO}_{2}$ at $37^{\circ} \mathrm{C}$. The HepG2, PLC, and Huh7 cells were seeded into 6-cmdiameter plates at $3-8 \times 10^{5}$ cells/well. Twenty-four hours after seeding, the cells were transfected with CDC25A AS oligonucleotides, mismatch-1 oligonucleotides (MM-1), or mismatch-2 oligonucleotides (MM-2) $(0.2 \mu \mathrm{M}$ for HepG2 and PLC; $0.25 \mu \mathrm{M}$ for Huh7), complexed with transfection reagent (Oligofectamine for HepG2 and PLC; Lipofectamine ${ }^{\mathrm{TM}}$ 2000 for Huh7; Invitrogen, Carlsbad, CA). The siRNA oligonucleotides ( $4 \mu \mathrm{g} /$ well) were transfected with Lipofectamine 2000 reagent. The transfection was carried out according to the manufacturer's protocol.

Transfection efficiency. Transfection efficiency was evaluated using FITC-conjugated oligonucleotides. Cells were observed under fluorescence microscopy at 24, 48 and $72 \mathrm{~h}$ after transfection, and counted in a total of 10 fields at high magnification. Results were reported as the percentage of total number of cells.

Western blot analysis. Western blotting was performed as previously described (14). Twenty-five micrograms of the total protein was subjected to $10 \%$ PAGE, followed by electroblotting onto a polyvinylidene difluoride (PVDF) membrane. After blocking in 5\% skim milk, the membrane was incubated with $1 \mu \mathrm{g} / \mathrm{ml}$ CDC25A antibody, followed by the secondary antibody (1:2000). The enhanced chemiluminescence Western blot detection system (Amersham, Aylesbury, UK) was used to detect the immunocomplex. CDC25A, MT3-MMP (Santa Cruz Biotechnology, Santa Cruz, CA), and actin (Sigma) antibodies were used at a dilution of $1: 200,1: 2000$, and 1:1000, respectively.
Growth curves. Cells were uniformly seeded (5x103/well for HepG2 and PLC; 2x103/well for Huh7) in duplicate onto 6well plates. Twenty-four hours later, the culture medium was removed and replaced with $1 \mathrm{ml}$ fresh medium containing each oligonucleotide $(0.2 \mu \mathrm{M}$ in HepG2 and PLC cultures; $0.25 \mu \mathrm{M}$ in Huh7 cultures) and transfection reagent. Cells were counted using a hemocytometer at the indicated times. Experiments were repeated at least twice.

Cell cycle analysis. Cells were washed twice with PBS, fixed in $70 \%$ cold ethanol for $4 \mathrm{~h}$, and washed and re-suspended in $1 \mathrm{ml}$ of PBS. Propidium iodide (Sigma, $50 \mu 1 \mathrm{of} 1 \mathrm{mg} / \mathrm{ml}$ solution in PBS) and RNase (Sigma, $1 \mu 1$ of $10 \mathrm{mg} / \mathrm{ml}$ solution) were added for $30 \mathrm{~min}$ at $37^{\circ} \mathrm{C}$. Samples were filtered through $44-\mu \mathrm{m}$ nylon mesh, and data were acquired using a FACSort (Becton Dickinson Immunocytometry Systems, San Jose, CA). Analysis of the cell cycle was performed using ModFIT software (Becton Dickinson Immunocytometry Systems). Experiments were repeated at least twice.

Invasion assay. An in vitro invasion assay was performed as previously described (21). Briefly, Transwells ${ }^{\mathrm{TM}}$ (Costar, Cambridge, MA) with $8-\mu$ m-pore-size polycarbonate membrane filters in 24-well culture plates were used. The upper surface of the filter was coated with Matrigel (Becton Dickinson, Bedford, MA) in a volume of $12.5 \mu \mathrm{g}$ per filter; the Matrigel was dried and reconstituted at $37^{\circ} \mathrm{C}$ into a solid gel on the filter surface. The lower surface of the filter was coated with fibronectin $(20 \mu \mathrm{g} / \mathrm{ml})$, vitronectin $(10 \mu \mathrm{g} / \mathrm{ml})$, collagen IV $(50 \mu \mathrm{g} / \mathrm{ml})$, or $1 \%$ bovine serum albumin (BSA), used as chemoattractants. The cells treated with oligonucleotides for $24 \mathrm{~h}$ were seeded in the upper chamber at a density of $2 \times 10^{5}$ cells/insert for HepG2 and $5 \times 10^{4}$ cells/insert for PLC and Huh7. HepG2 and Huh7 cells were allowed to invade for $24 \mathrm{~h}$ and PLC cells for $48 \mathrm{~h}$. Cells that invaded the lower surface of the filter were counted in ten random fields under a light microscope at high magnification. Experiments were repeated at least twice.

Reverse transcriptase-polymerase chain reaction. Reverse transcriptase-polymerase chain reaction (RT-PCR) was performed in a $25-\mu 1$ total volume of reaction mixture containing $1 \mu \mathrm{l}$ cDNA template, $1 \mathrm{X}$ Perkin Elmer PCR buffer, $1.5 \mathrm{mM} \mathrm{MgCl}_{2}, 0.8 \mathrm{mM}$ deoxynucleotide triphosphates, 20 pmol primer for porphobilinogen deaminase (PBGD), CDC25A, albumin, MMPs (MMP2, MT1-MMP, MT2MMP, MT3-MMP) and 1 unit of TaqDNA polymerase (AmpliTaq Gold, Roche Molecular Systems, Inc., Belleville, $\mathrm{NJ}$ ). Reverse transcription (RT) was performed at $42^{\circ} \mathrm{C}$ for $90 \mathrm{~min}$ and then at $95^{\circ} \mathrm{C}$ for $10 \mathrm{~min}$. PCR was performed with specific primers in $25-\mu 1$ volumes containing $2.0 \mu \mathrm{g} \mathrm{RT}$ products according to the manufacturer's protocol.

The primer sequences of CDC25A, PBGD, and albumin were previously described $(14,22)$. The primers for MMPs were as follows (23): MMP-2 forward, 5'-ACC TGG ATG CCG TCG TGG AC-3' and MMP-2 reverse, 5'-TGT GGC AGC ACC AGG GCAGC-3'; MT1-MMP forward, 5'-ACA TCA AAG TCT GGG AAG GGA-3' and MT1-MMP reverse, 5'-AGC AGG GAA CGC TGG CAG T-3'; MT2-MMP forward, 5'-CAG CCC AGC CGC CAT ATG TC-3' and 
HuH7

\section{$24 \mathrm{~h}$}

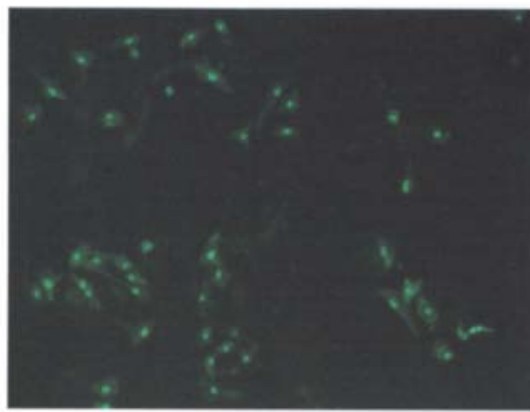

$48 \mathrm{~h}$

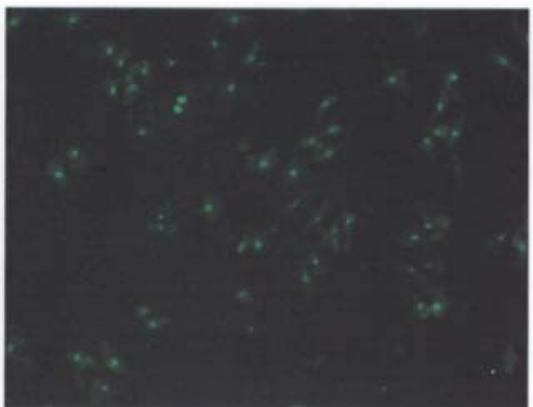

$72 \mathrm{~h}$

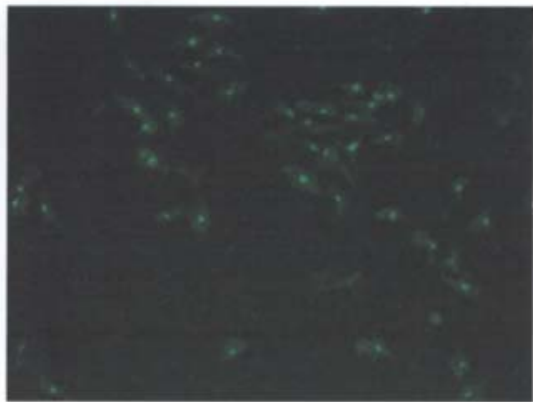

Figure 1. Representative figures of Huh7 cells after transfection with FITC-conjugated antisense (AS) oligonucleotides. Cell count indicated transfection efficiency at $84.1,88.0$ and $89.7 \%$ at 24,48 and $72 \mathrm{~h}$, respectively.

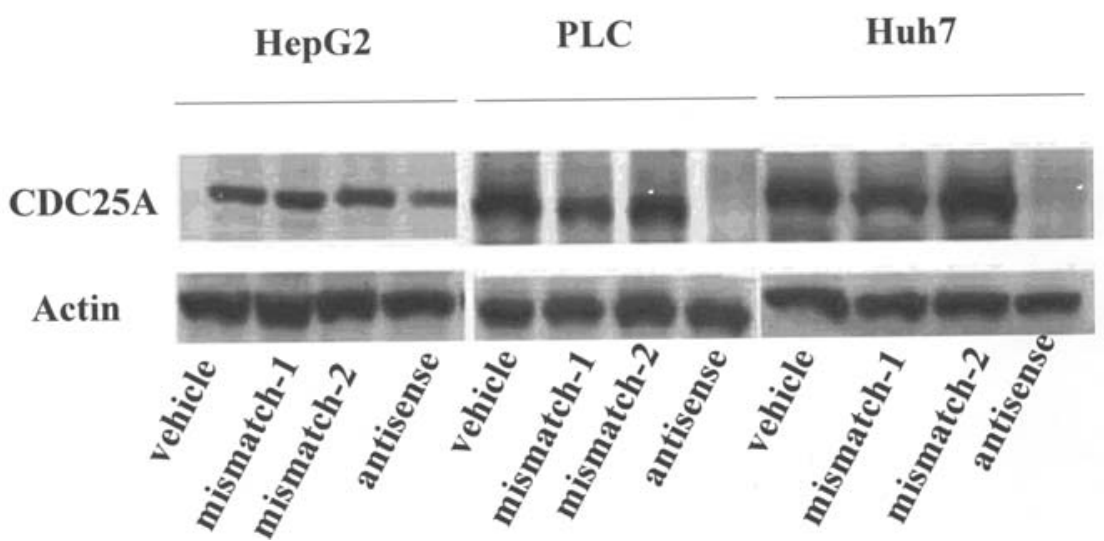

Figure 2. AS oligonucleotide to CDC25A decreased CDC25A expression in HCC cells. Three HCC cell lines were transfected with vehicle alone, vehicle plus MM oligonucleotides, or AS oligonucleotides. Cells were harvested $48 \mathrm{~h}$ after transfection. The protein lysates were subjected to Western blot analysis with anti-CDC25A and anti-actin antibody. Actin bands indicate equal loading of the protein.

MT2-MMP reverse, 5'-CTT TCA CTC GTA CCC CGA AC3'; MT3-MMP forward, 5'-ACA GTC TGC GGA ACG GAG CAG-3' and MT3-MMP reverse, 5'-GTC AAT TGT GTT TCT GTC CAC-3'.

Statistical analysis. Data were expressed as the mean \pm SEM. Group differences were examined for statistical significance using the Mann-Whitney U test or Fisher's exact test. Mean values were compared using the Student's t-test. A $p<0.05$ denoted a statistically significant difference.

\section{Results}

Transfection efficiency. Representative figures of cells transfected with FITC-conjugated oligonucleotides are shown in Fig. 1. PLC cells had a lowest transfection efficiency, with an average of $18.8 \pm 4.57$ and $19.5 \pm 5.76 \%$ for AS and MM2, respectively. A tendency of reduction of efficiency with time was noted. A lower efficiency was found for MM1 at $13.2 \pm 0.23 \%$. A slightly higher efficiency was noted in HepG2; $29.6 \pm 4.20 \%$ for AS, $30.3 \pm 1.08 \%$ for MM2 and similarly a lower rate of $21.9 \pm 7.47 \%$ for MM1. Reduction of efficiency with time was only observed for MM1. The highest transfection efficiency was observed for Huh7; 87.2 $2.79 \%$,
$87.5 \pm 1.23 \%$ and $86.7 \pm 5.48$ for $\mathrm{AS}, \mathrm{MM} 1$ and MM2 respectively.

Suppression of CDC25A with antisense oligonucleotides. We used Western blotting to examine the expression of CDC25A protein in HepG2, PLC, and Huh7 HCC cell lines treated with vehicle alone or vehicle plus each oligonucleotide (AS, MM-1, or MM-2) $48 \mathrm{~h}$ after transfection. As shown in Fig. 2, the AS oligonucleotide suppressed CDC25A levels by $60 \%$ in HepG 2 cells and by $95 \%$ in PLC and Huh7 cells. On the other hand, when we examined $\mathrm{CDC} 25 \mathrm{~B}$ expression no reduction was obtained by AS-CDC25A (data not shown).

Cell growth and cell cycle. AS to CDC25A significantly inhibited cell growth of HepG2, PLC, and Huh7 cells. Statistical significance between cultures treated with AS oligonucleotide versus other oligonucleotides is shown in Fig. 3A. We then performed flow cytometric analysis $24 \mathrm{~h}$ after transfection. In the three HCC cell types tested, treatment with AS oligonucleotide increased the G0-G1 phase fraction and decreased the $\mathrm{S}$ phase fraction when compared to vehicletreated cultures. Repeat experiments of cell growth and cell cycle analyses gave similar results. A representative result is shown in Fig. 3B with the following fraction values for 
A

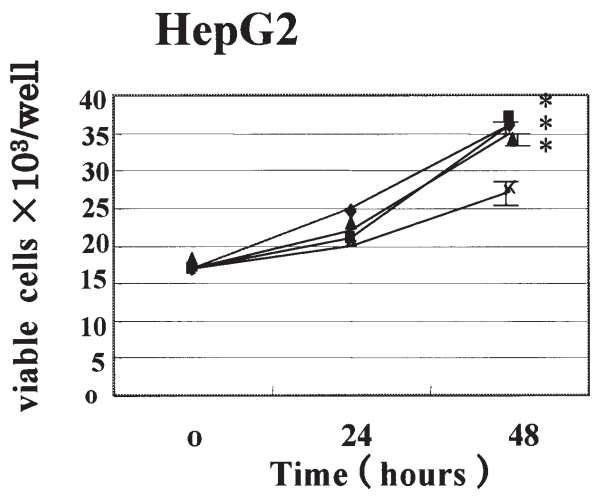

Huh7

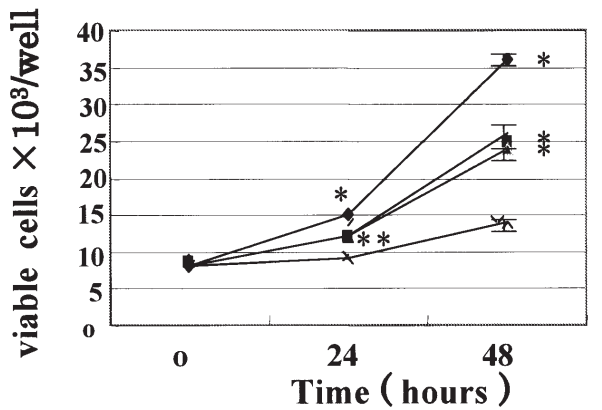

B
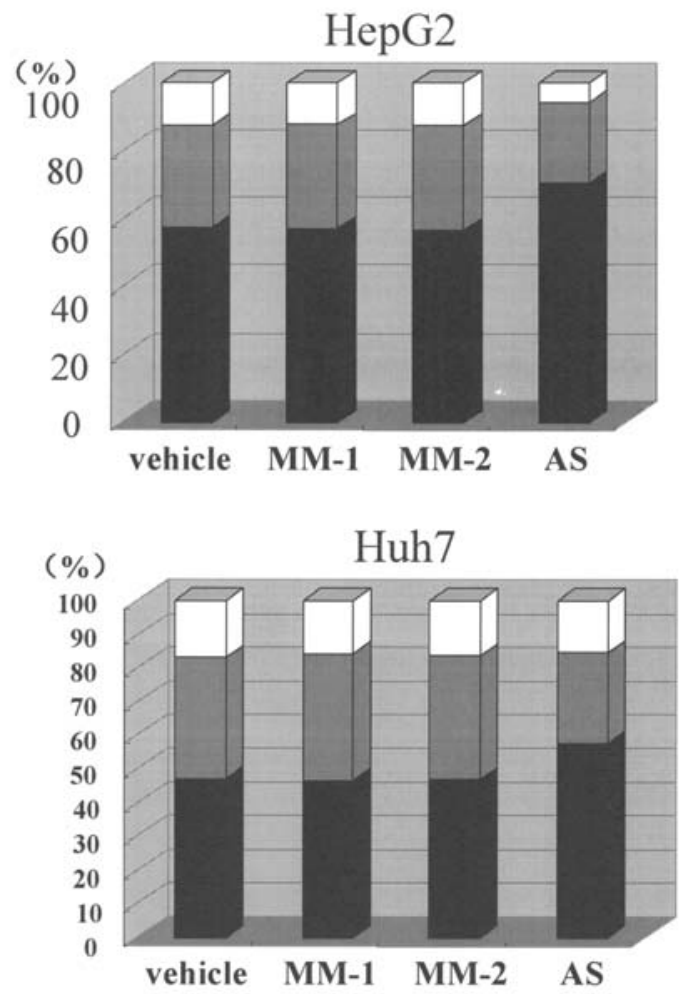
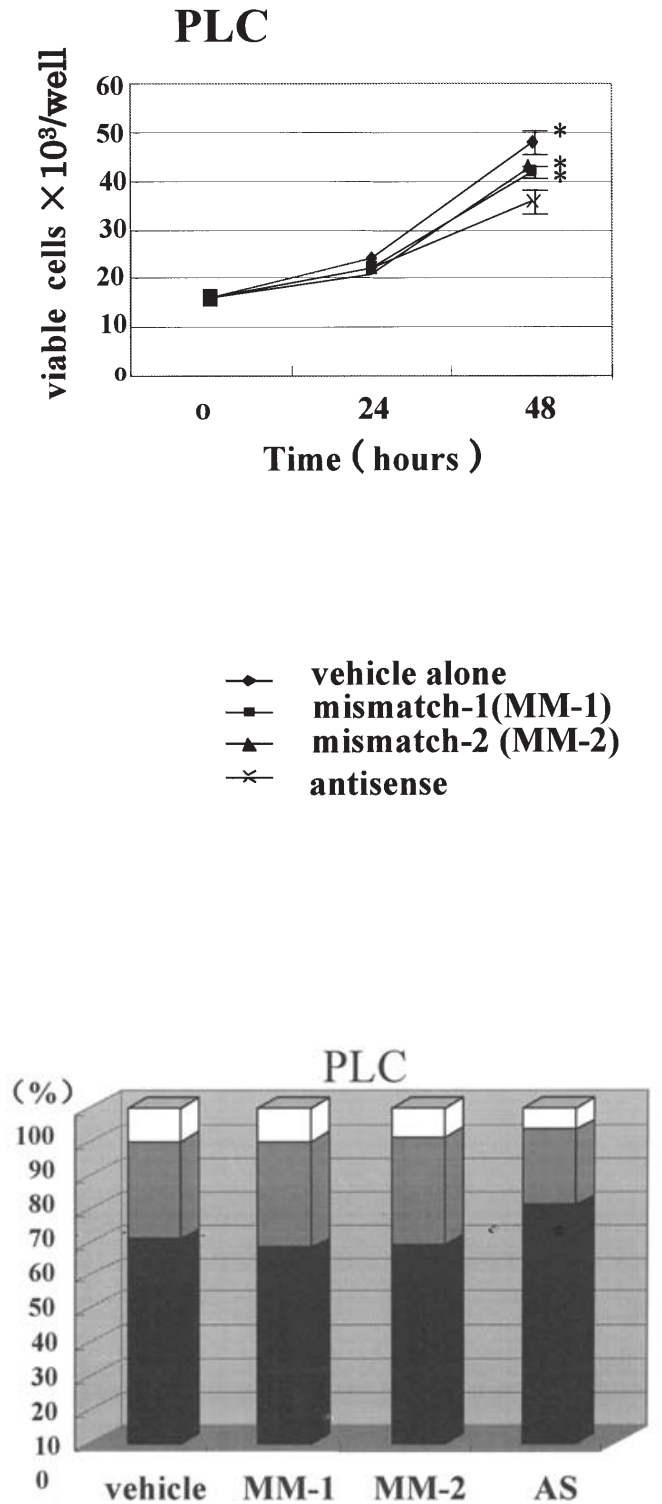

vehicle MM-1 MM-2 AS

Figure 3. (A) Proliferation assay in response to CDC25A AS oligonucleotide. Treatment with AS to CDC25A resulted in significant growth delay in HepG2 and PLC cells at $48 \mathrm{~h}$ when compared to treatment with vehicle alone, MM-1, and MM-2 ( ${ }^{*} \mathrm{p}<0.05$ for each comparison to AS). Similar effects were observed in Huh7 cells at 24 and $48 \mathrm{~h}$ ( ${ }^{*} \mathrm{p}<0.05$ for each comparison to AS). The data represent the averages from two separate experiments. (B) Cell cycle analysis. Treatment with AS oligonucleotide for $24 \mathrm{~h}$ increased the G0-G1 phase fraction and decreased the S phase fraction in HCC cells when compared to vehicletreated cultures. These effects were not obtained with MM-1 or MM-2 oligonucleotide treatment.

cultures treated with AS oligonucleotide versus vehicle, respectively: G0-G1; HepG2, $57.2 \%$ and $70.4 \%$; PLC, $60.8 \%$ and $70.8 \%$; Huh7, $47.1 \%$ and $58.4 \%$; and $\mathrm{S}$ phase fraction;
HepG2, 30.4\% and 23.3\%; PLC, 29.1\% and 23.0\%; Huh7, $36.19 \%$ versus $27.2 \%$ (Fig. 3B). No such effects were found with MM-1 or MM-2 oligonucleotides. 


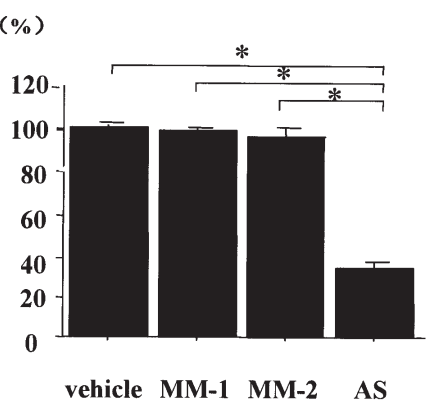

HepG2

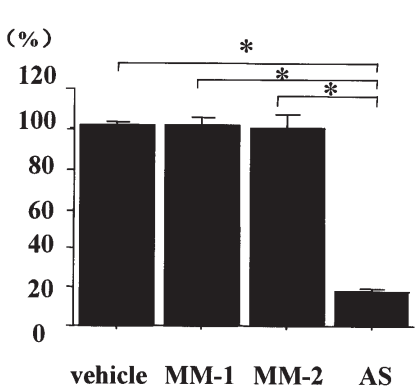

PLC
* $\mathbf{p}<0.01$

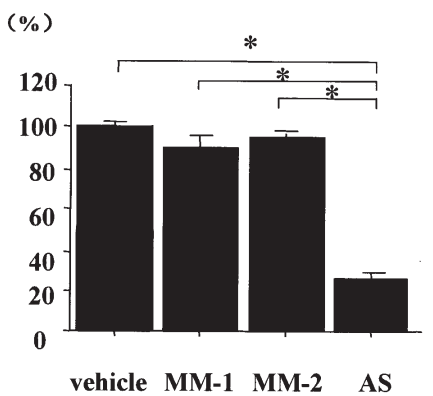

Huh7

Figure 4. Invasion assay. AS to CDC25A decreased invasion by HCC cells. The assay was performed in duplicate; bars indicate the mean \pm SD. A significant reduction in cell invasion was noted in AS-treated cultures versus cultures treated with vehicle, MM-1, and MM-2 ( $\left.{ }^{*} \mathrm{p}<0.01\right)$.

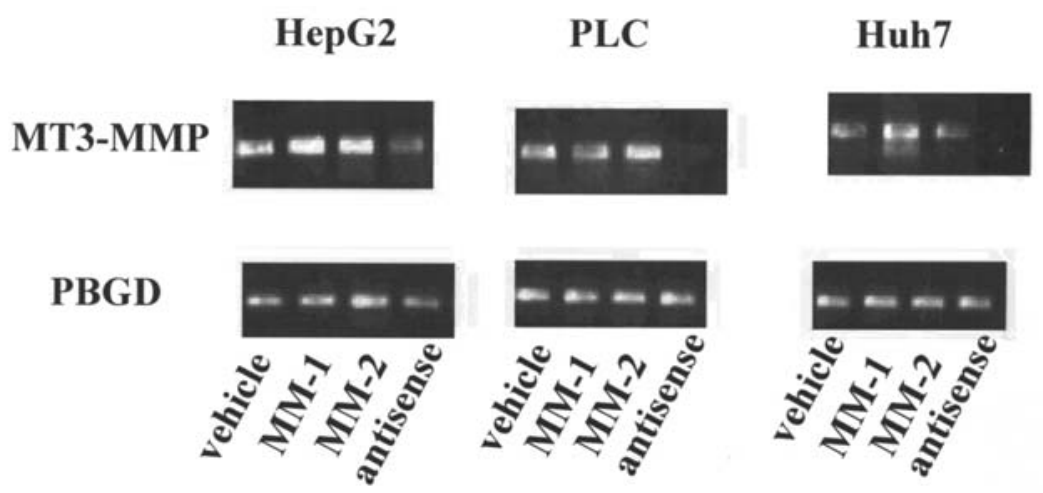

Figure 5. AS to CDC25A decreased MT3-MMP mRNA expression in HCC cells. Cells were harvested $24 \mathrm{~h}$ after transfection and examined for MT3-MMP mRNA by RT-PCR assay. PBGD, a housekeeping gene, served as the control. HCC tissues were used as positive control for MT3-MMP mRNA.

Invasive ability. To investigate the effect of AS to CDC25A on the invasive ability of HCC cells we performed an invasive assay. When compared to vehicle treatment, AS to CDC25A significantly suppressed cancer cell invasion by $33.2 \%$ in HepG2 cells $(\mathrm{p}=0.002), 17.2 \%$ in PLC cells $(\mathrm{p}=0.001)$, and $26.5 \%$ in Huh7 cells ( $\mathrm{p}=0.001$ ) (Fig. 4). These inhibitory effects were not found with MM-1 or MM-2 treatment. A repeat experiment showed similar results.

Expression of matrix metalloproteinases. To investigate the underlying mechanism for the inhibitory effect of AS to CDC25A on the invasive ability of HCC cells, we used RTPCR to examine the expression of a series of matrix metalloproteinases (MMP). These included MMP2, MT1-MMP, MT2-MMP, and MT3-MMP. We found that AS to CDC25A decreased MT3-MMP mRNA expression in all three HCC cell lines (Fig. 5). However, expression of the other MMPs was unaffected (data not shown). To confirm the results, we investigated the effect of siRNA against CDC25A. Western blot analysis showed that the reduction in CDC25A expression was associated with a large reduction in MT3-MMP protein in the three HCC cell lines (Fig. 6).

We then investigated mRNA expression of MMP2, MT1MMP, MT2-MMP, and MT3-MMP in a variety of gastrointestinal tumor cell lines including HCC cell lines. MT3MMP expression, when compared to that of other MMPs, was relatively specific to the HCC cell lines (expression rate by cell lines, 7/7:100\%) versus other gastrointestinal tumor cell lines such as pancreatic cancer $(2 / 5: 40 \%)$, colon cancer $(0 / 5$ : $0 \%)$, gastric cancer $(1 / 5: 20 \%)$, and esophageal cancer $(1 / 3: 33 \%)$ cell lines (Table 1$)$.

Restoration of albumin expression in PLC by CDC25A inhibition. We investigated whether inhibition of CDC25A restores cell differentiation in HCC cell lines, using albumin expression as a marker of differentiation (24). We found that the PLC cell line which marginally expressed albumin showed an increase in albumin mRNA expression following treatment with AS oligonucleotide (Fig. 7). siRNA treatment against CDC25A showed a similar result (Fig. 7). However, there was no change in albumin mRNA expression in the remaining two HCC cell lines that had relatively high albumin levels (data not shown). We should also emphasize that this was not the case with other liver-specific functions such as APOCIII or asialoglycoprotein receptor, and glutathione-S-transferase- $\pi$ (data not shown).

\section{Discussion}

In our earlier study of CDC25A expression in human HCC tissue samples we found that high CDC25A expression was associated with cell proliferation, portal vein invasion, and 
Table I. Expression of MMP mRNA in gastrointestinal cancer cell lines.

\begin{tabular}{|c|c|c|c|c|c|c|c|}
\hline & \multicolumn{7}{|c|}{ Hepatocellular carcinoma cell lines } \\
\hline & HLE & HLF & Huh7 & PLC & HepG2 & SKHep1 & PLL \\
\hline MMP2 & + & + & + & + & + & + & + \\
\hline MT1-MMP & - & + & + & + & - & + & + \\
\hline MT2-MMP & + & + & + & + & + & + & + \\
\hline \multirow[t]{3}{*}{ MT3-MMP } & + & + & + & + & + & + & + \\
\hline & \multicolumn{5}{|c|}{ Pancreatic cancer cell lines } & & \\
\hline & PANC1 & PSN-1 & PCL-6 & $\mathrm{MiaPaCa}$ & AsPC-1 & & \\
\hline MMP2 & + & + & + & - & + & & \\
\hline MT1-MMP & + & + & + & + & + & & \\
\hline MT2-MMP & + & + & + & + & + & & \\
\hline \multirow[t]{3}{*}{ MT3-MMP } & + & - & + & - & - & & \\
\hline & \multicolumn{5}{|c|}{ Colon cancer cell lines } & & \\
\hline & LoVo & HT29 & DLD1 & HCT116 & SW480 & & \\
\hline MMP2 & - & - & - & - & + & & \\
\hline MT1-MMP & + & - & - & - & + & & \\
\hline MT2-MMP & + & + & + & + & + & & \\
\hline \multirow[t]{3}{*}{ MT3-MMP } & - & - & - & - & - & & \\
\hline & \multicolumn{5}{|c|}{ Gastric cancer cell lines } & & \\
\hline & MKN-1 & MKN-28 & MKN-74 & MKN-45 & KATO-III & & \\
\hline MMP2 & + & - & - & + & - & & \\
\hline MT1-MMP & + & + & - & + & + & & \\
\hline MT2-MMP & + & + & + & + & + & & \\
\hline \multirow[t]{3}{*}{ MT3-MMP } & + & - & - & - & - & & \\
\hline & \multicolumn{3}{|c|}{ Esophageal cancer cell lines } & & & & \\
\hline & TE-2 & TE-8 & $\mathrm{TT}$ & & & & \\
\hline MMP2 & + & + & + & & & & \\
\hline MT1-MMP & + & + & + & & & & \\
\hline MT2-MMP & + & + & + & & & & \\
\hline MT3-MMP & - & - & + & & & & \\
\hline
\end{tabular}

dedifferentiated histology (14). Accordingly, we here examined the effects of CDC25A inhibition on cell cycle, growth, invasion, and differentiation of HCC cell lines. Since CDC25A is a cell cycle accelerator, it is likely that inhibition of CDC25A leads to cell cycle delay and results in growth inhibition. However, we demonstrated that CDC25A inhibition was associated with reduction of MT3-MMP in the three HCC cell lines and an increase in albumin level in the PLC HCC cell line. These findings were further confirmed by siRNA treatment.

We found that CDC25A AS oligonucleotide inhibited cell growth and induced G0-G1 arrest in HCC cell lines. These results were anticipated based on the knowledge that
CDC25A is a crucial regulator of the cell cycle, acting at the G1-S transition (5). However, the present findings cannot be underestimated because uncontrolled cell growth plays a particularly integral role in the progression of HCC. Indeed, several reports have shown that the expression of proliferating cell nuclear antigen (PCNA) and Ki-67 is significantly associated with HCC relapse $(25,26)$. This is in contrast to colon cancer, where proliferative activity alone appears not to result in fatal events $(27,28)$. Furthermore, our previous study provided direct evidence that CDC25A expression correlates well with PCNA expression in human HCC tissue samples (14). Taken together, these findings suggest that inhibition of CDC25A may have therapeutic potential for 


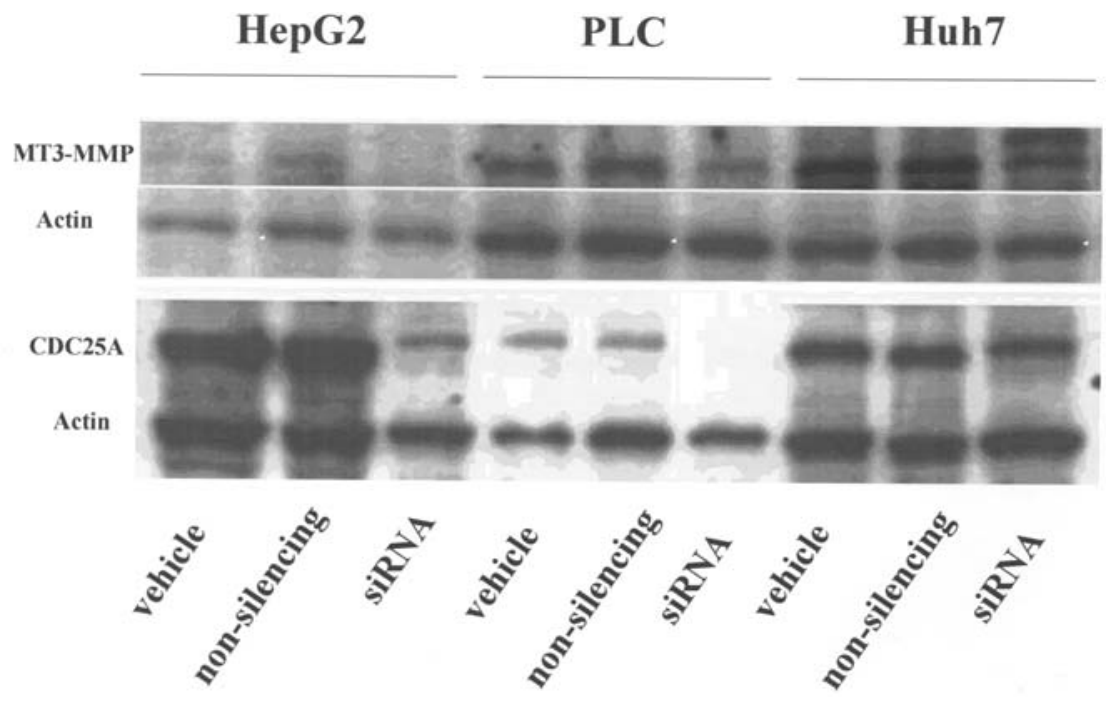

Figure 6. MT3-MMP protein expression was suppressed by siRNA against CDC25A. Cells were collected $48 \mathrm{~h}$ after transfection. Inhibition of CDC25A expression by siRNA caused downregulation of MT3-MMP protein expression in HCC cells. By contrast, a non-silencing sequence did not alter CDC25A or MT3-MMP levels. Actin blots served as a loading control.

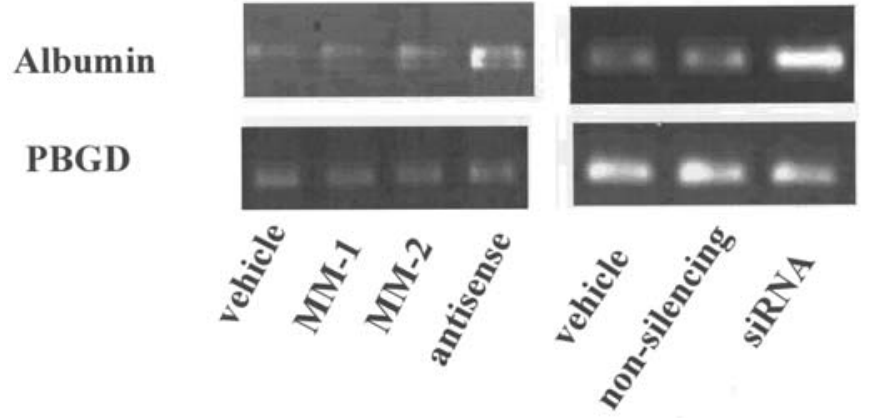

Figure 7. Inhibition of CDC25A induced albumin mRNA expression in PLC cells. AS to CDC25A and siRNA against CDC25A induced expression of albumin mRNA as early as $12 \mathrm{~h}$ after treatment. PBGD served as the control.

HCC by restraining growth, which may lead to prolonged disease-free survival.

We also found that AS to CDC25A inhibited the invasive activity of HCC cell lines. This finding is particularly important because HCC invades vessel walls and metastasizes inside the liver, which is considered a major cause of death from the disease $(29,30)$. It may be argued that the inhibitory effects of AS to CDC25A on cancer cell invasion may simply reflect reduced tumor cell growth. We cannot rule out such a possibility. Yet based on the demonstrated downregulation of MT3-MMP in all three HCC cell lines it is likely that the invasive ability itself may be regulated by AS to CDC25A. MT3-MMP, one of the major MMPs, was originally cloned from human melanoma tissue and human placenta and is expressed in a variety of normal and tumor tissues (22,31-33). Functional expression of MT3-MMP in human WM1341D melanoma cells facilitated in vitro collagen I invasion (34). Also, expression of MT3-MMP in hamster CHO-K1 and canine MDCK cells induced the expression of a fibrininvasive phenotype (35). When we examined the mRNA expression of MMP2, MT1-MMP, MT2-MMP, and MT3MMP in HCC and gastrointestinal cancer cell lines, we found that MT3-MMP expression was rather specific to HCC cell lines. Moreover, we recently found that MT3-MMP expression was associated with tumor invasion in primary HCC tissues (36). Although the precise mechanism of how CDC25A regulates MT3-MMP should be determined at the next stage of research, these findings suggest the relevance of MT3-MMP to invasion in HCC.

Our previous study showed that CDC25A expression was associated with dedifferentiated histology of HCC (14). In the present mechanistic study, we found upregulation of albumin mRNA in PLC cells treated with CDC25A AS. It is reported that PLC produces albumin scarcely, while Huh-7 and HepG2 cells produce high albumin levels (37-39), which is consistent with current findings. The difference in basal albumin level may account for restoration of albumin expression only in PLC cells. Human HCC is unique in that tumor growth occurs relatively slowly and with a welldifferentiated phenotype in the early stage but faster and with dedifferentiation in the advanced stage $(40,41)$. In this context, inhibition of CDC25A may convert advanced HCC into a more differentiated and less aggressive phenotype; at least certain types of HCC cells.

In conclusion, antagonism of CDC25A inhibited the growth and invasion of HCC cells, possibly via cell cycle arrest at G0-G1 and suppression of MT3-MMP expression. Taken together, these findings strongly suggest that CDC25A may be a promising therapeutic target against HCC. Indeed, several CDC25A inhibitors are being developed, including novel vitamin $\mathrm{K}$ analogues and steroidal-derived inhibitors $(42,43)$.

\section{Acknowledgements}

This study was supported by a Grant-in Aid for Cancer Research from the Ministry of Education, Science, Sports, Culture, and Technology, Japan to H.Y. 


\section{References}

1. WHO: The World Health Report, 2000

2. Kumada T, Nakano S, Takeda I, et al: Patterns of recurrence after initial treatment in patients with small hepatocellular carcinoma. Hepatology 25: 87-92, 1997.

3. Shimada M, Takenaka K, Gion T, et al: Prognosis of recurrent hepatocellular carcinoma; a 10-year surgical experience in Japan. Gastroenterology 111: 720-726, 1996.

4. Galaktionov K and Beach D: Specific activation of cdc25 tyrosine phosphatases by B-type cyclins: evidence for multiple roles of mitotic cyclins. Cell 67: 1181-1194, 1991

5. Jinno S, Suto K, Nagata A, et al: Cde25A is a novel phosphatase functioning early in the cell cycle. EMBO J 13: 1549-1556, 1994

6. Nagata A, Igarashi M, Jinno S, Suto K and Okayama H: An additional homolog of the fission yeast cdc25+ gene occurs in humans and is highly expressed in some cancer cells. New Biol 3: 959-968, 1991

7. Sadhu K, Reed SI, Richardson H and Russell P: Human homolog of fission yeast cdc25 mitotic inducer is predominantly expressed in G2. Proc Natl Acad Sci USA 87: 5139-5143, 1990.

8. Galaktionov K, Lee AK, Eckstein J, et al: CDC25 phosphatases as potential human oncogenes. Science 269: 1575-1577, 1995.

9. Cangi MG, Cukor B, Soung P, et al: Role of the Cdc25A phosphatase in human breast cancer. J Clin Invest 106: 753-761, 2000.

10. Gasparotto D, Maestro R, Piccinin S, et al: Overexpression of CDC25A and CDC25B in head and neck cancers. Cancer Res 57: 2366-2368, 1997

11. Hernandez S, Hernandez L, Bea S, et al: Cdc25 cell cycleactivating phosphatases and c-myc expression in human nonHodgkin's lymphomas. Cancer Res 58: 1762-1767, 1998.

12. Nishioka K, Doki Y, Shiozaki H, et al: Clinical significance of CDC25A and CDC25B expression in squamous cell carcinomas of the oesophagus. Br J Cancer 85: 412-421, 2001.

13. Wu W, Fan YH, Kemp BL, Walsh G and Mao L: Overexpression of cdc25A and cdc25B is frequent in primary nonsmall cell lung cancer but is not associated with overexpression of c-myc. Cancer Res 58: 4082-4085, 1998.

14. Xu X, Yamamoto H, Sakon M, et al: Overexpression of CDC25A phosphatase is associated with hypergrowth activity and poor prognosis of human hepatocellular carcinomas. Clin Cancer Res 9: 1764-1772, 2003.

15. Ito Y, Matsuura N, Sakon M, et al: Expression and prognostic roles of the G1-S modulators in hepatocellular carcinoma: p27 independently predicts the recurrence. Hepatology 30: 90-99, 1999.

16. Masaki T, Shiratori Y, Rengifo W, et al: Cyclins and cyclindependent kinases: comparative study of hepatocellular carcinoma versus cirrhosis. Hepatology 37: 534-543, 2003.

17. Hui AM, Sakamoto M, Kanai Y, et al: Inactivation of p16INK4 in hepatocellular carcinoma. Hepatology 24: 575-579, 1996.

18. Hui AM, Kanai Y, Sakamoto M, Tsuda H and Hirohashi S: Reduced p21(WAF1/CIP1) expression and p53 mutation in hepatocellular carcinomas. Hepatology 25: 575-579, 1997.

19. Blomberg I and Hoffmann I: Ectopic expression of Cdc25A accelerates the $G(1) / S$ transition and leads to premature activation of cyclin E- and cyclin A-dependent kinases. Mol Cell Biol 19: 6183-6194, 1999.

20. Sandhu C, Donovan J, Bhattacharya N, Stampfer M, Worland P and Slingerland J: Reduction of Cdc25A contributes to cyclin E1-Cdk2 inhibition at senescence in human mammary epithelial cells. Oncogene 19: 5314-5323, 2000

21. Albini A: Tumor and endothelial cell invasion of basement membranes. The matrigel chemoinvasion assay as a tool for dissecting molecular mechanisms. Pathol Oncol Res 4: 230-241, 1998.

22. Gion T, Taketomi A, Shimada M, et al: Perioperative change in albumin messenger RNA levels in patients with hepatocellular carcinoma. Hepatology 28: 1663-1668, 1998.

23. Kitagawa Y, Kunimi K, Uchibayashi T, Sato H and Namiki M: Expression of messenger RNAs for membrane-type 1,2, and 3 matrix metalloproteinases in human renal cell carcinomas. J Urol 162: 905-909, 1999.
24. Krishna M, Lloyd RV and Batts KP: Detection of albumin messenger RNA in hepatic and extrahepatic neoplasms: A marker of hepatocellular differentiation. Am J Surg Pathol 21: $147-152,1997$

25. King KL, Hwang JJ, Chau GY, et al: Ki-67 expression as a prognostic marker in patients with hepatocellular carcinoma. J Gastroenterol Hepatol 13: 273-279, 1998.

26. Ng IO, Lai EC, Fan ST, Ng M, Chan AS and So MK Prognostic significance of proliferating cell nuclear antigen expression in hepatocellular carcinoma. Cancer 73: 2268-2274, 1994.

27. Jansson A and Sun XF: Ki-67 expression in relation to clinicopathological variables and prognosis in colorectal adenocarcinomas. APMIS 105: 730-734, 1997.

28. Kubota Y, Petras RE, Easley KA, Bauer TW, Tubbs RR and Fazio VW: Ki-67-determined growth fraction versus standard staging and grading parameters in colorectal carcinoma. A multivariate analysis. Cancer 70: 2602-2609, 1992.

29. Sakon M, Umeshita K, Nagano H, et al: Clinical significance of hepatic resection in hepatocellular carcinoma: analysis by disease-free survival curves. Arch Surg 135: 1456-1459, 2000.

30. Yamanaka J, Yamanaka N, Nakasho K, et al: Clinicopathologic analysis of stage II-III hepatocellular carcinoma showing early massive recurrence after liver resection. J Gastroenterol Hepatol 15: $1192-1198,2000$

31. Nuttall RK, Pennington CJ, Taplin J, et al: Elevated membranetype matrix metalloproteinases in gliomas revealed by profiling proteases and inhibitors in human cancer cells. Mol Cancer Res 1: 333-345, 2003.

32. Ohnishi Y, Tajima S and Ishibashi A: Coordinate expression of membrane type-matrix metalloproteinases-2 and -3 (MT2-MMP and MT3-MMP) and matrix metalloproteinase-2 (MMP-2) in primary and metastatic melanoma cells. Eur J Dermatol 11 420-423, 2001

33. Yoshiyama Y, Sato H, Seiki M, Shinagawa A, Takahashi M and Yamada T: Expression of the membrane-type 3 matrix metalloproteinase (MT3-MMP) in human brain tissues. Acta Neuropathol 96: 347-350, 1998.

34. Iida J, Pei D, Kang T, et al: Melanoma chondroitin sulfate proteoglycan regulates matrix metalloproteinase-dependent human melanoma invasion into type I collagen. J Biol Chem 276: 18786-18794, 2001.

35. Hotary KB, Yana I, Sabeh F, et al: Matrix metalloproteinases (MMPs) regulate fibrin-invasive activity via MT1-MMPdependent and -independent processes. J Exp Med 195: 295-308, 2002.

36. Arai I, Nagano H, Kondo M, et al: Overexpression of MT3-MMP in hepatocellular carcinoma correlates with capsular invasion. Hepatogastroenterology 54: 167-171, 2007.

37. Macnab GM, Alexander JJ, Lecatsas G, Bey EM and Urbanowicz JM: Hepatitis B surface antigen produced by a human hepatoma cell line. Br J Cancer 34: 509-515, 1976.

38. Nakabayashi H, Taketa K, Miyano K, Yamane T and Sato J: Growth of human hepatoma cell lines with differentiated functions in chemically defined medium. Cancer Res 42: 3858$3863,1982$.

39. Zannis VI, Breslow JL, SanGiacomo TR, Aden DP and Knowles BB: Characterization of the major apolipoproteins secreted by two human hepatoma cell lines. Biochemistry 20: 7089-7096, 1981.

40. Kenmochi K, Sugihara S and Kojiro M: Relationship of histologic grade of hepatocellular carcinoma (HCC) to tumor size, and demonstration of tumor cells of multiple different grades in single small HCC. Liver 7: 18-26, 1987.

41. Kojiro M: Pathology of early hepatocellular carcinoma progression from early to advanced. Hepatogastroenterology 45 1203-1205, 1998.

42. Peng H, Xie W, Otterness DM, et al: Syntheses and biological activities of a novel group of steroidal derived inhibitors for human Cdc25A protein phosphatase. J Med Chem 44: 834-848, 2001.

43. Wang Z, Southwick EC, Wang M, et al: Involvement of CDC25A phosphatase in Hep3B hepatoma cell growth inhibition induced by novel $\mathrm{K}$ vitamin analogs. Cancer Res 61: $7211-7226,2001$. 